Nennung des bei der Reservierung erhaltenen Codewortes öffnete sich eine nicht ohne weiteres sichtbare Tür in einer weiteren Wand und gab uns den Weg in die Bar frei.

Erholung von der Stadt und den zahlreichen Streifzügen durch die New Yorker Nächte findet sich in den Sommermonaten an den Stränden von Long Island, nach einer knapp einstündigen Zugfahrt kann man dort wunderbar entspannen und muss sich angesichts der Ruhe und der Weitläufigkeit dort immer wieder vor Augen führen, dass die Weltstadt nur einen Katzensprung entfernt ist. Natürlich laden auch die Hamptons dazu ein, den Lärm der Stadt bei einer Fahrradtour mit anschließendem Bad im Ozean hinter sich zu lassen.

Wer einmal etwas weiter hinaus möchte aus New York, der kann beispielsweise Städte wie Washington D. C. oder Boston besuchen. Diverse Busunternehmen bieten beinahe stündlich Reisen dorthin an und nach etwa vierstündiger Fahrt ist die Hauptstadt der Vereinigten Staaten bzw. von Massachusetts erreicht.

Die Ausführungen über das Leben und meine Erlebnisse in Manhattan ließen sich mannigfach erweitern. Zusammenfassend kann ich jedenfalls festhalten:

Ich habe den gesamten Aufenthalt meiner Wahlstation in New York City keinen einzigen Tag bereut. Den Sommer in dieser Stadt so unmittelbar nach dem schriftlichen Examen verbringen zu können, war eine einmalige Erfahrung, die ich sicherlich nie im Leben vergessen werde.

\title{
Veranstaltungshinweise
}

\section{Feministischer Juristinnentag}

\section{6.-8. Mai 2011 in der FH Frankfurt a.M.}

Veranstalterin ist der Verein „Frauen streiten für ihr Recht e.V.“, Frankfurt a.M. In der feministischen Rechtszeitschrift STREIT werden jeweils die Resolutionen und Programme, wie auch einzelne Vorträge publiziert.

Im Bereich des Familienrechts soll es um das gemeinsame Sorgerecht sowie die Gesetzentwürfe zum Sorgerecht nicht mit der Mutter verheirateter Väter gehen. Darüber hinaus werden Fragen des Unterhaltsrechts und die Gestaltung von Eheverträgen aufgegriffen. Ein arbeitsrechtlicher Schwerpunkt wird sich mit dem Thema Arbeitsmarkt, Wirtschaftskrise und ihre Auswirkungen auf Frauen befassen. Zusätzlich werden aktuelle Diskussionen (Mindestlohn, Arbeitszeit u.ä.) aufgegriffen. Einige Angebote richten sich speziell an Nebenklagevertreterinnen (Glaubhaftigkeitsgutachten, Fragen der Kooperation mit der psychosozialen Prozessbegleitung und Opferentschädigung). Daneben sollen aber auch „Täterinnen“ Thema sein. Eine weitere AG wird sich mit aktuellen aufenthaltsrechtlichen Themen befassen. Schließlich ist ein Forum zur inneren Sicherheit geplant, das Themen wie Terrorismus, häusliche Gewalt und Diskriminierung einschließt. Das Programm und weitere Informationen: http://www.feministischer-juristinnentag.de/index.html und in der STREIT.

\section{EWLA-Kongress}

\section{6.-27. Mai 2011 in Malta}

Der Kongress steht unter dem Motto „Empowering Women Lawyers across Europe through Networking in the Pursuit of Justice“. Sprechen wird u.a. Dr. Viviane Reding, Vizepräsidentin der Europäischen Kommission und Kommissarin für Justiz, Grundrechte und Bürgerschaft. Programm: http://www. ewla.org/.

\section{Anwältinnenkonferenz - DAT 2011}

\section{2.-4. Juni 2011 in Straßburg}

Die Arbeitsgemeinschaft Anwältinnen veranstaltet ihre 13. Anwältinnenkonferenz im Rahmen des Deutschen Anwaltstages in Straßburg. Die Themen am 2. Juni 2011, 14.00 bis 16.00 Uhr sind: „Sexualisierte Kriegsgewalt vor Internationalen Strafgerichten“ unter Mitwirkung von Dr. Monika Hauser (Gründerin und geschäftsführendes Vorstandsmitglied von medica mondiale e.V., Köln), Dr. Kathrin Greve, LL.M., Berlin, Claudia Hoefer (International Criminal Tribunal for the former Yugoslavia, Den Haag), Mag. Renate Winter (Richterin in der Berufungskammer des Spezialgerichtshofs von Sierra Leone (SCSL), Den Haag), Prof. Dr. Dr. h.c. Angelika Nußberger, M.A. (Richterin am Europäischen Gerichtshof für Menschenrechte, Straßburg), Mechtild Düsing (Rechtsanwältin, Münster).

Von 16.30 bis 18.00 Uhr geht es um „Europa ist weiblich. Anwältinnen in Deutschland, Frankreich und der Schweiz Anwältinnen an die Macht und in die Aufsichtsräte" unter Mitwirkung von Avivah Wittenberg-Cox (Autorin und Beraterin in Gender-Angelegenheiten, „WHY \& HOW Women Mean Business - A Walk around Womenomics“, Paris), Dr. Maria Wolleh (Rechtsanwältin, Partnerin von Mannheimer Swartling Advokatbyrå AB und Secretary for IBA's Women Lawyers' Interest Group, Berlin), Valérie Tandeau de Marsac (Rechtsanwältin, Partnerin von Jeantet Associés, Gründerin und Präsidentin von voxfemina, Paris), Ines Pöschl (Rechtsanwältin, Partnerin von Kellerhals Anwälte, Zürich), Dr. Barbara Mayer (Rechtsanwältin, Geschäftsführende Partnerin Friedrich Graf von Westphalen \& Partner, Freiburg).

Der Frühstücksempfang am 3. Juni 2011, 8.30-9.30 Uhr ist offen für Mitglieder, Interessentinnen und Interessenten. Moderation: Rechtsanwältin Dr. Eva-Dorothee Leinemann, Berlin.

Weitere Informationen: http://www.dav-anwaeltinnen.de/ und http://www.anwaltverein.de/DAT. 